\title{
„Ein Tag wie der andere“
}

\section{Bericht eines Achtzehnjährigen}

6.30 Uhr: Strom geht an

6.50 Uhr: Öffnen der Zellentüren

6.50 - 7.00 Uhr: Zeit für Frühstück holen

7.00 - 7.15 Uhr: Frühstücken in der Zelle und Fertigmachen

7.15 Uhr: Abrücken zur Arbeit

7.30 - $9.00 \mathrm{Uhr}: \quad$ Arbeit

$9.00-9.15$ Uhr: Frühstückspause

9.15 - 11.30 Uhr: Arbeit

11.30 - 12.15 Uhr: Mittagessen in Kantine und Pause

12.15 - $15.20 \mathrm{Uhr}: \quad$ Arbeit

$15.20-15.30 \mathrm{Uhr}$ : Sicherheitskontrollen und Zellengang

15.50 - $16.50 \mathrm{Uhr}$ : Hofgang

17.30 Uhr: Ausgabe vom Abendessen in Zelle und Müllabgabe

$18.00-21.30 \mathrm{Uhr}$ Freizeit im wöchentlichem Wechsel für je eine Stockwerksseite (Billard, Kicker, Kraftsport)

21.30 Uhr: Zelleneinschluss

$1.00 \mathrm{Uhr}$ : Strom wird abgedreht 